\title{
LA-UR-97- 3158
}

Approved tor public release; distribution is unlimited

\section{Title: $\begin{aligned} & \text { The Implications of Diffraction in situ Loading } \\ & \text { Macro-Strain Measurements in Composites }\end{aligned}$ \\ Title: $\mid \begin{aligned} & \text { The Implications of Diffraction in situ Loading } \\ & \text { Macro-Strain Measurements in Composites }\end{aligned}$ \\ Title: $\mid \begin{aligned} & \text { The Implications of Diffraction in situ Loading } \\ & \text { Macro-Strain Measurements in Composites } \\ & \text { and Finite Element Interpretations }\end{aligned}$}

\author{
$\sec 20$ \\ DEC $0 ? 19 \mathrm{PM}$ \\ 031 \\ Author(s): N. Shi, LER-MLNSC (currently at IBM) \\ M. A. Bourke, MST-5 \\ J. A. Roberts, LER-MLNSC
}

Submitted to:

DOE Office of Scientific and Technical Information (OSTI)

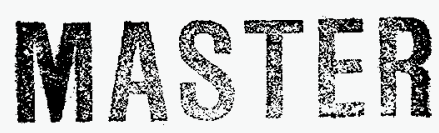

\section{Los Alamos}

NATIONAL LABORATORY

Los Alamos National Laboratory, an affirmative action/equal opportunity employer, is operated by the University of Calitornia for the U.S. Department of Energy under contract W-7405-ENG-36. By acceptance of this article, the publisher recognizes that the U.S. Government retains a nonexclusive, royaltyfree license to publish or reproduce the published form of this contribution, or to allow others to do so, for U.S. Government purposes. Los Alamos National Laboratory requests that the publisher identify this article as work performed under the auspices of the U.S. Department of Energy. Los Alamos National Laboratory strongly supports academic freedom and a researcher's right to publish; as an institution, however, the Laboratory does not endorse the viewpoint of a publication or guarantee its technical correctness. 


\section{DISCLAIMER}

This report was prepared as an account of work sponsored by an agency of the United States Government. Neither the United States Government nor any agency thereof, nor any of their employees, makes any warranty, express or implied, or assumes any legal liability or responsibility for the accuracy, completeness, or usefulness of any information, apparatus, product, or process disclosed, or represents that its use would not infringe privately owned rights. Reference herein to any specific commercial product, process, or service by trade name, trademark, manufacturer, or otherwise does not necessarily constitute or imply its endorsement, recommendation, or favoring by the United States Government or any agency thereof. The views and opinions of authors expressed herein do not necessarily, state or reflect those of the United States Government or any agency thereof. 


\section{DISCLamigR}

Portions of this doearnent may be illegible in electronic image products. Images are produced from the best arailable ariginal docoment 


\title{
TheImplications of Diffraction in-situ Loading Macro-Strain Measurements in Composites and Finite Element Interpretations
}

\author{
Ning Shi ${ }^{*}$, Mark A. Bourke ${ }^{\ddagger}$, and Joyce A. Roberts
}

\begin{abstract}
This is the final report of a three-year, Laboratory Directed Research and Development (LDRD) project at the Los Alamos National Laboratory (LANL). The main objective of the project is to show that diffraction strain measurement, when complemented with numerical tools, can provide insights that traditional metallurgical methods cannot offer. In this project, we concentrate on issues concerning discontinuously reinforced metal and intermetallic matrix composites. We have studied load transfer between phases during loading, internal stress distribution during and as a result of inelastic stress relaxation (creep). We also studied the signatures of reinforcement fracture on the evolution of average elastic global strain, and used neutrons to study the micromechanics of slip in intermetallic composites. Of these subjects, we have found, most importantly, that the ratio of load partition in multiphase material does not stay as a constant; internal damage in composites leaves a distinct signature on the evolution of global average elastic strain; and, in reinforced low-symmetry materials, stress relaxation is dictated by the micromechanics of crystal slip, which cannot be accounted for by the continuum theory.
\end{abstract}

\section{Background and Research Objectives}

Internal stresses, load-induced or residual, directly affect the performance of composites. Characterization of this quantity is important to improving composite mechanical properties. Neutron diffraction is a technique that probes into material to measure internal elastic strain nondestructively. However, because of the relatively large beam size used in the neutron diffraction technique (compared to material microstructure) only information representing a volume average (average microstresses) can be extracted from this method. One approach to complement this method is to couple it with a micromechanical model which, when validated, extends spatial resolution to a finer scale providing details at microstructure level. The finite-element method (FEM) has been used for such a purpose. When validated by an experimental technique, FEM is a powerful tool to reveal internal stress distribution resulting from interactions between microstructures with complex shapes and morphology in materials.

To date, neutron diffraction has been used as a validation tool to verify numerical models for engineering predictions. An example of current ongoing projects at Los Alamos

Principal Investigator, current E-mail: shi@vnet.ibm.com

${ }^{\ddagger}$ LANL contact, E-mail: bourke@lanl.gov 
National Laboratory (LANL) is a Collaborative Research and Development Agreement (CRADA) with automotive industries that explores heat distortion. Neutron diffraction has been playing a major part in the CRADA. However, internal stress development is related to many physical phenomena in material beyond internal stresses per se. It is therefore important to study signatures from the internal stresses evolution, which provide direct or indirect information on other related deformation processes, such as plastic flow and creep. The benefits are two-fold: we will not be restricted to the nondestructive evaluation (NDE) of stresses by its "face value" only, and we will show that we can address a wider audience on other topics of common interest using internal stresses as a tool. More importantly, we can reach out to the rest of the materials science community to show that neutron diffraction strain measurement is an important technique that can address their common interest, which may seem, at first glance, unrelated to internal stresses.

The main objective of this LDRD project is to show that diffraction strain measurement, when complemented by numerical tools, can provide insights that traditional metallurgical/material methods cannot offer. In this project, we concentrate on issues concerning discontinuously reinforced metal and intermetallic matrix composites. We have studied load transfer during loading and internal stress distribution during and as a result of inelastic stress relaxation (creep). We also studied the signatures of reinforcement fracture on the evolution of average elastic global strain, and we used neutrons to study the micromechanics of slip in intermetallic composites.

\section{Importance to LANL's Science and Technology Base and National R\&D Needs}

The Neutron Lab is a Laboratory technical goal. It is important to explore the potential of neutron diffraction to its maximum. It is already established that neutron diffraction strain measurement is a valid engineering tool for NDE of material internal stresses. To fully utilize this potential, complementary development of modeling capability tailored to diffraction measurement is important. To further enhance the importance of strain measurements/modeling, it is vital to understand what other issues within materials science and other disciplines related to internal stresses development can be better addressed by strains than any other existing methods. This is beneficial to the developing Science-Based Stockpile Stewardship (SBSS) program at the Manuel Lujan Neutron Scattering Center (MLNSC) at Los Alamos. This in-house knowledge is also beneficial to the Basic Energy Sciences (BES) user program in the Department of Energy (DOE), Office of Energy Research (OER), in that the knowledge can be used to educate potential external users to attract them to use the facility to satisfy their needs. 


\section{Scientific Approach and Accomplishments}

We have used the existing experimental set-up (stress-rig)at MLNSC to measure both residual and load-induced internal elastic strain in composites. We developed FEM models and the data were first used to validate the models. Then stress distributions calculated by FEM were used to obtain information on a finer scale since diffraction results only represent a spatial average of information at the scale of the material microstructures. The calculated/measured results were used to study subjects of common interest in composites such as (1) load sharing during loading, (2) internal damage accumulation, (3) internal stress variation during and after inelastic creep deformation, and (4) relaxation of thermal mismatch in reinforced low-symmetry materials.

\section{(1) Load Sharing in Composites During Loading}

Using neutron diffraction we measured, during in situ loading, the lattice elastic mean phase (LEMP) strains in the matrix and reinforcement of a $15 \mathrm{vol} \% \mathrm{TiC}$ particulate reinforced $2219 \mathrm{Al}$ composite. From the strain components longitudinal and transverse to loading, the in situ normal phase stresses were obtained through Hooke's Law. Stress partition between matrix and reinforcement, i.e. load sharing, can then be inferred. Internal stress development was also modeled using FEM showing good agreement with the experimental results. Both indicate that the relationship between the LEMP strains (and corresponding stresses) and the applied load deviates from linearity after the onset of matrix plasticity. The nonlinearity arises because the applied traction is not synonymous with the phase stresses, i.e.,the ratio of phase stresses may vary during the loading process. Notably the morphology of the LEMP strain development with applied load differs in the directions perpendicular or parallel to the load (Fig. 1). FEM calculations indicate that the change in curvature shown in Fig. 1 comes from the matrix plasticity, and initial propagation of matrix plasticity induces curvature changes that are different from those from a complete plastic matrix. We have further shown that the presence of thermal residual stresses affects the initiation of matrix plasticity, and therefore the morphology of the LEMP strain evolution. Details are given in $[1,2]$.

\section{(2) Characterization of Reinforcement Fracture}

We have developed a method, based on diffraction lattice strain measurements, to characterize internal damage accumulation and changes in the stored internal elastic strain energy following uniaxial external loading. Using neutron diffraction, we measured the elastic phase strains of $\mathrm{AV} / \mathrm{TiC}$ and $\mathrm{Al} / \mathrm{SiC}$ composites under uniaxial tensile loading. The phase strains were used to reconstruct the global average elastic strain of the specimen from 
the condition of displacement continuity. It has been found that, above the sample macroscopic yield, the global average elastic strain response is nonlinear. Theoretical derivations show that the nonlinearity is dictated by the changes in the ratio of phase normal stresses along the loading direction. The slope can be rigorously expressed as

$$
\text { slope }=\frac{\left(\lambda_{\text {matrix }}+2 G_{\text {matrix }}\right)[1+f(R-1)]}{1+f\left[\frac{R}{E_{\text {paricle }}}\left(\lambda_{\text {matrix }}+2 G_{\text {matrix }}\right)-1\right]}
$$

where $\lambda, G$, and $E$ are material constants, and $R$ is the instantaneous load partition ratio defined as $R=\Delta \sigma_{i} / \Delta \sigma_{m}$. Figure 2 shows the reconstructed stress vs. average elastic strain curve from an $\mathrm{Al}$ composite, reinforced by spherical $\mathrm{TiC}$ particles, compared with that calculated from Eq. 1, with R calculated from FEM.

The observed nonlinearity is useful in NDE in multiphase materials in two aspects: (1) since internal damage such as reinforcement fracture induces load transfer between phases, the associated changes in slope from the nonlinear average global elastic response can be used to characterize the evolution of internal damage and (2) the hysteresis loop accompanying the nonlinearity following a load-unload cycle provides an indicator to benchmark the changes in stored elastic strain energy resulting from the loading process. Figure 3 shows a similar curve from another $\mathrm{Al}$ composite, reinforced by angular $\mathrm{SiC}$ particles, in which reinforcements are confirmed to fracture during loading [3,4]. A twotone slope change is apparent. For more details see [3]. A comprehensive study of the particle shape effect on the reinforcement damage was also conducted to complement the current diffraction study $[4,5]$.

\section{(3) Internal Stress Variation During and After Inelastic Creep Deformation}

Matrix creep at room temperature may take place while diffraction data is being taken at a constant load. Such time-dependent deformation may also lead to time-dependent load transfer. To illustrate the effect of in-situ creep on the development of global average elastic strain, a series of strain measurements was sequentially made at a constant load at which creep was believed to be significant. Figure 4 shows the development of global mean elastic strain with time measured at different constant load levels of 400,410 and 425 $\mathrm{MPa}$, respectively. The arrow in the figure points to the direction of time increase. The entire time-span for all measurements at $400 \mathrm{MPa}$ is about four hours. As shown in Fig. $4 \mathrm{~b}$, only at the onset of creep flow ( $400 \mathrm{Mpa})$ is the change in the global mean elastic strain significant. Although the magnitude of global creep strain at $425 \mathrm{MPa}$ is similar to that at 
$400 \mathrm{MPa}$ (Fig. 5), the corresponding changes in global mean elastic strain are much smaller (Fig. 4b).

FEM calculations have shown a similar trend. Internal flow contours from FEM have shown that the initial changes in the global elastic strain are due to the evolution of matrix creep flow under load. Therefore, stress repartition occurs during loading as indicated by the decrease in global mean elastic strain shown in Fig. 4. The slope is related to load partition by Eq. 1. As the load increases (at $425 \mathrm{MPa}$ after unloading from 450 $\mathrm{MPa}$ ), the entire matrix has undergone creep. Since deformation is in the steady-state creep regime and distortion is not large enough for geometrical nonlinearity to be significant, time-dependent load transfer due to time-dependent change in both material behavior and geometry is limited.

We have also measured residual stresses following a series of isochronal creep under different constant creep loads. Compared with statically compressed samples, we have found that creep from loads lower than the nominal macroscopic yield point induces relaxation of matrix residual strain (Fig. 6). When the deformation mode is a combination of time-dependent creep and instantaneous time-independent plasticity, matrix residual strain increases. A model based on internal stress evolution from deformation incompatibilities was developed to explain the phenomenon [6].

\section{(4) Relaxation of Thermal Mismatch in Reinforced Low-Symmetry Intermetallics}

In this study, we have measured the dislocation density and thermal residual elastic strain in $\mathrm{NiAl}$ matrices of $20 \mathrm{vol} \% \mathrm{Al}_{2} \mathrm{O}_{3}$, discontinuously-reinforced composites. As the size of the reinforcement increases the average dislocation density increases, and the corresponding thermal residual elastic strains decrease (Fig. 7). The changes with respect to particle size in the dislocation density and residual strain can neither be explained by continuum theory nor by the continuum-based dislocation mechanics. A previously developed model (that satisfactorily describes the $\mathrm{SiC} / \mathrm{Al}$ system) suggests that the misfit dislocation density decreases with increase in reinforcement size, but this disagrees with the current $\mathrm{Al}_{2} \mathrm{O}_{3} / \mathrm{NiAl}$ results. A new model is proposed to describe low-symmetry intermetallics: low-symmetry materials are constrained in their ability to relax thermal mismatch because of a paucity of independent slip systems. A lack of sufficient independent slip systems in individual grains hinders plastic relaxation of thermal stresses as compared to $\mathrm{fcc} \mathrm{Al}$. As such, plastic relaxation requires collaborative slips in an aggregate of grains, which results only when the length scale of the varying misfit thermal stress field is much larger than the average grain size. That is, the mechanism of plastic relaxation becomes operative when the reinforcement size increases [6]. Results from 
polycrystalline plasticity calculations showed similar results in the magnitude of thermal residual stresses as a function of reinforcement size. As shown in Fig. 8, when the matrix has sufficient independent slip systems ( 3 independent slip systems-enough slip modes in two-dimensional models), the total amount of slip stays relative constant with the particle size; when the total number of independent slip systems in each grain reduces to one, the amount of slip increases with the particle size, consistent with the experiment.

\section{Publications/References}

1. N. Shi, M.A. M. Bourke, J. A. Roberts, and J. E. Allison: Met. Trans. A., submitted (1996).

2. N. Shi, M. A. M. Bourke, J. A. Roberts: Proceeding of the 4th International Conference of Residual Stresses, SEM, Bethel, CT., pp. 539, (1994).

3. N. Shi. M. A. M. Bourke, J. A. Roberts: Neutron Scattering in Materials Science II (ed. D. A. Neumann, T. P. Russell, B. J. Wuensch), MRS, Pittsburgh, PA, pp. 441 (1995).

4. S. G. Song, N. Shi, G. T. Gray III, and J. A. Roberts: Met. Trans. A., in the press, 1996.

5. N. Shi, S. G. Song, G. T. Gray III, J. A. Roberts: Proceedings of Professor Hans Weertman's 70th Birthday Symposium, TMS, Warrendale, PA, pp. 243 (1996).

6. N. Shi and R. J. Arsenault: Ann. Rev. Mat. Sci. vol. 24, pp.321 (1994).

7. N. Shi, R. J. Arsenault, M. A. M. Bourke, and J. A. Roberts: Micromechanics of Advanced Materials (ed. S. N. G. Chu et al.), TMS, Warrendale, PA, pp. 471 (1996). 

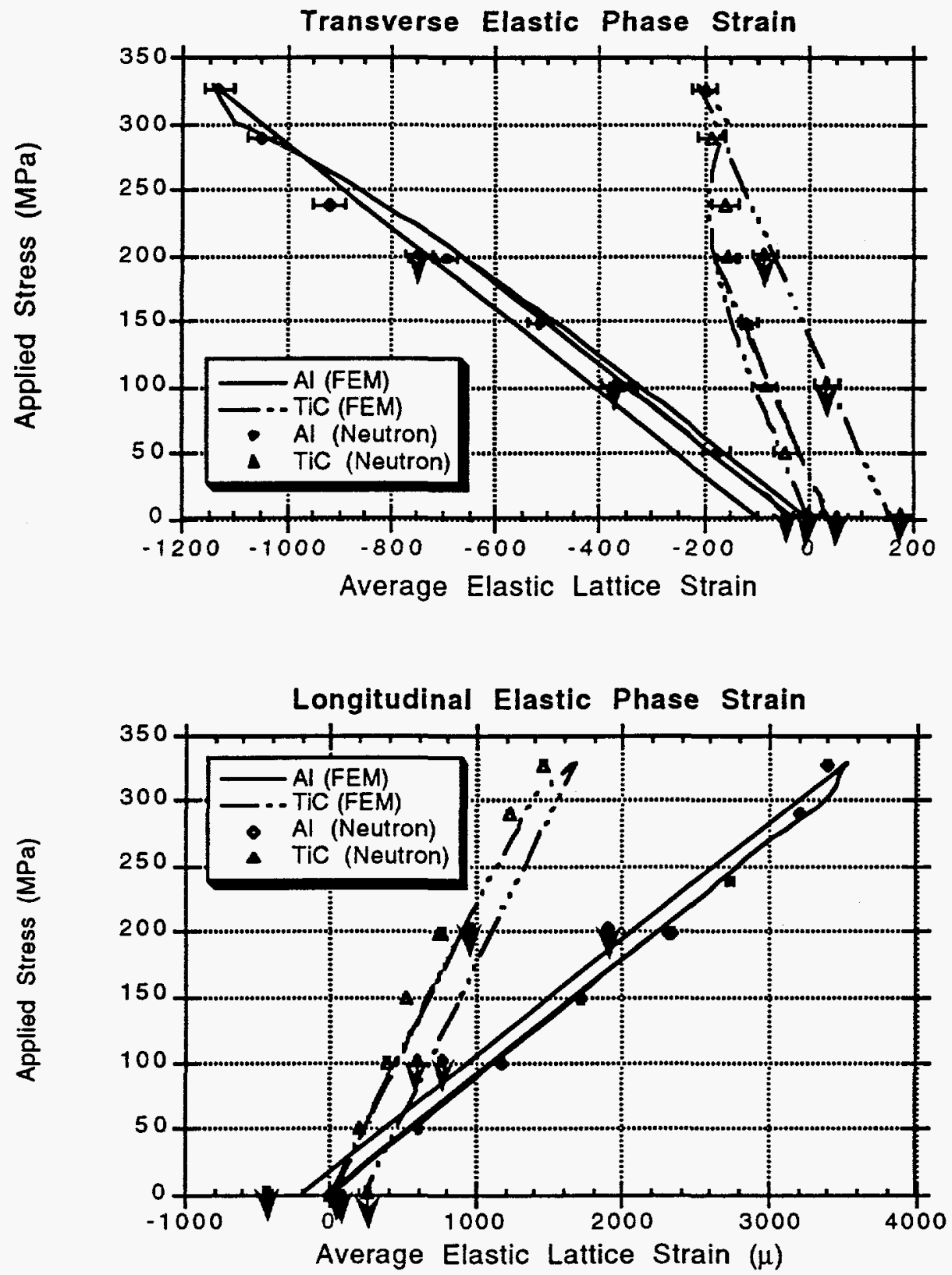

Figure 1: Load-induced changes in the transverse and longitudinal LEMP trains. Both measured and calculated elastic phase strains are plotted. Data points tagged with the symbol $(\downarrow)$ designate those measured during unload. 


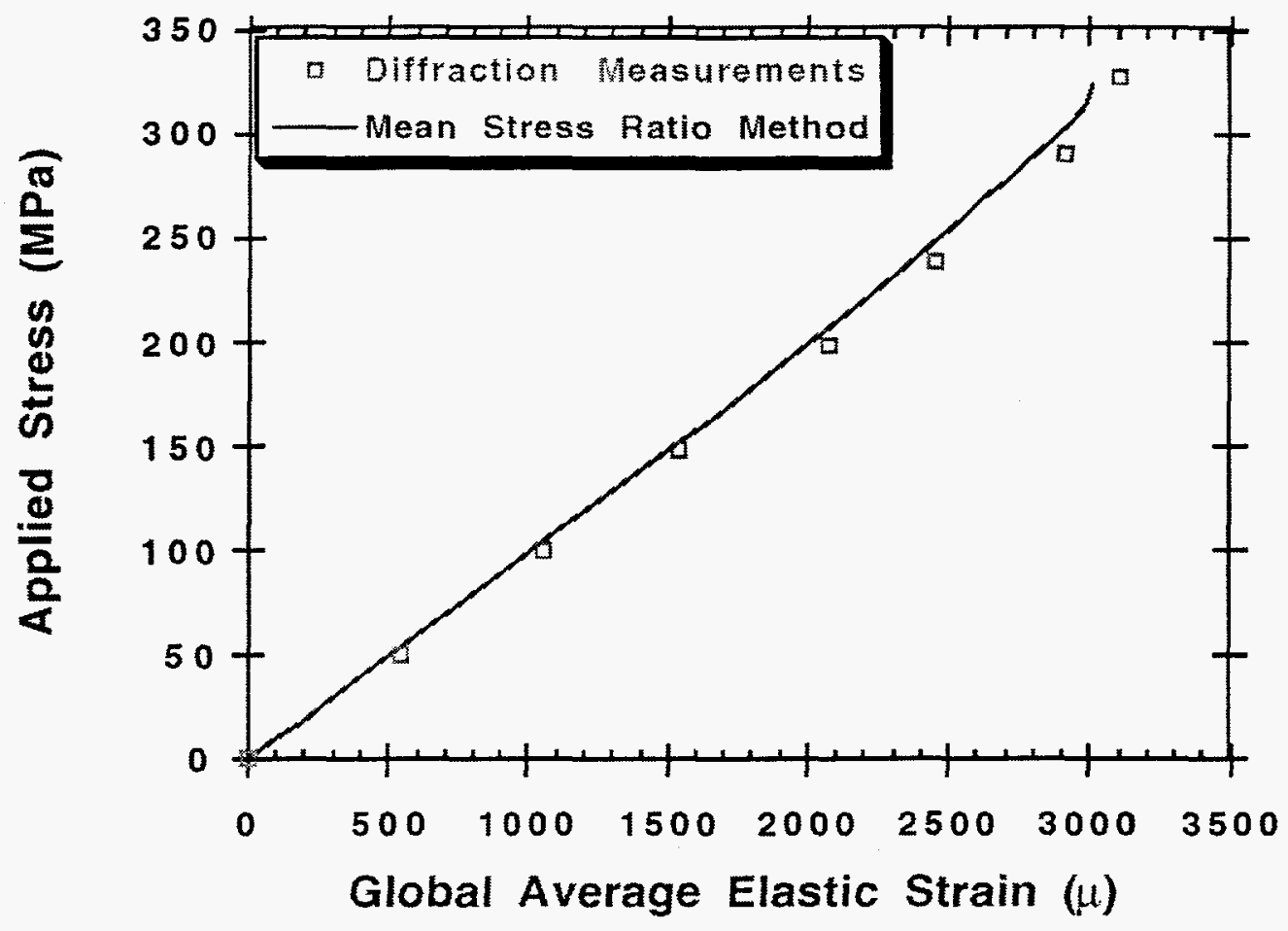

Figure 2: Evolution of reconstructed elastic average global strain in $\mathrm{Al} / \mathrm{TiC}$ as compared with model from Eq. 1.

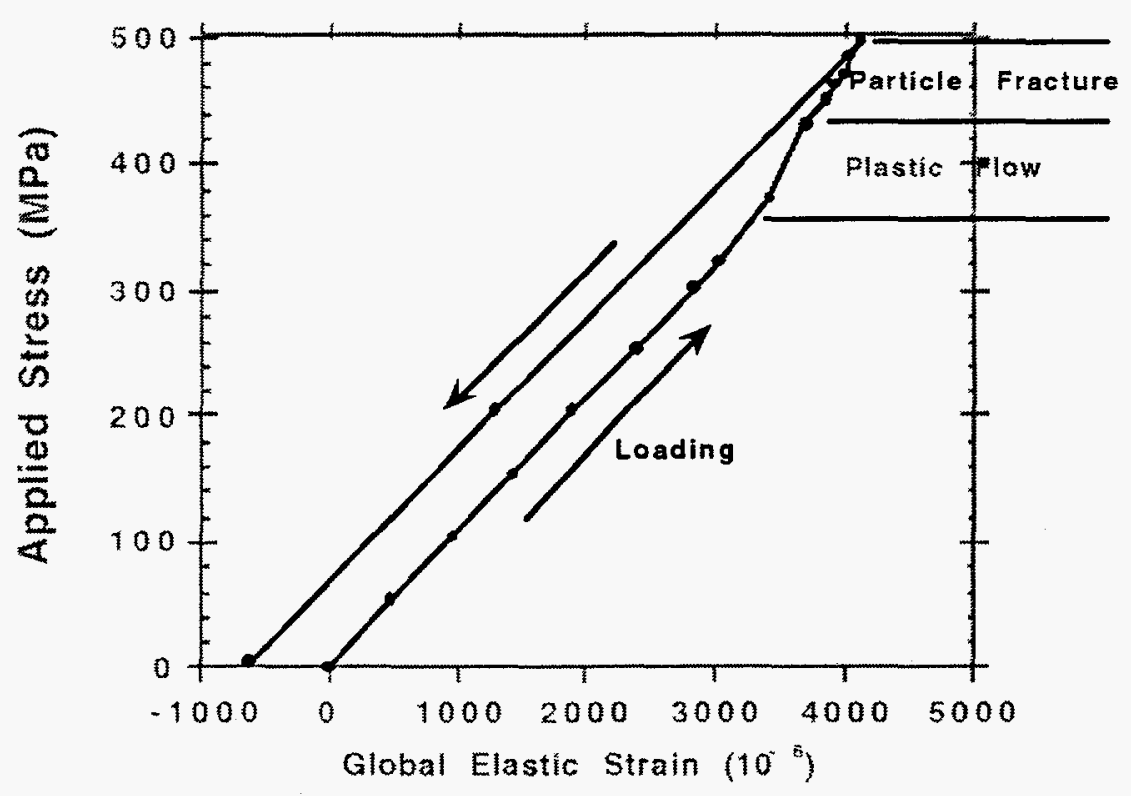

Figure 3: Evolution of reconstructed elastic average global strain in $\mathrm{Al} / \mathrm{SiC}$. 


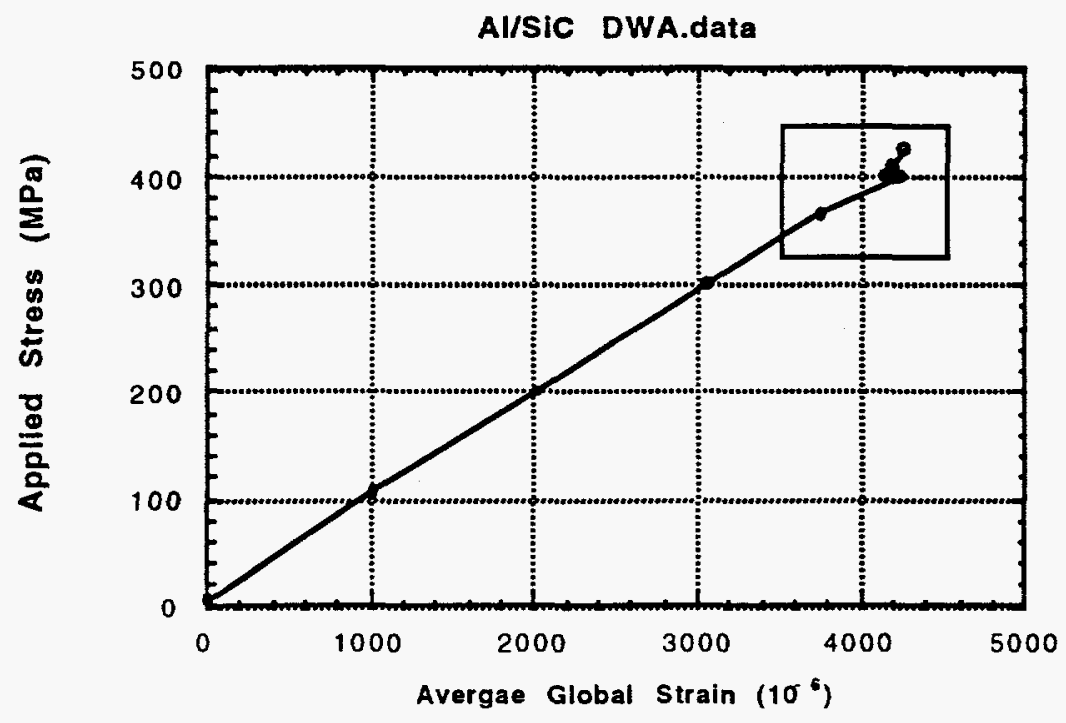

(a)

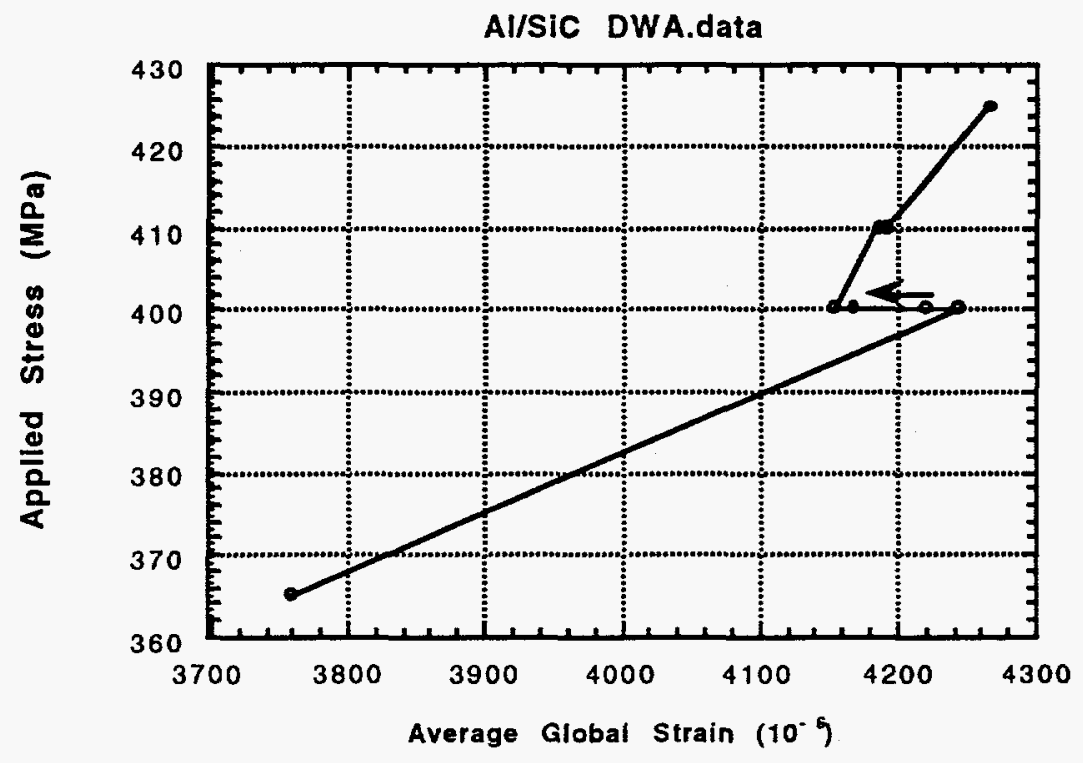

(b)

Figure 4: Development of elastic global average strain when matrix has undergone creep. (a) showing entire loading process; (b) zoom view of the creep region. 


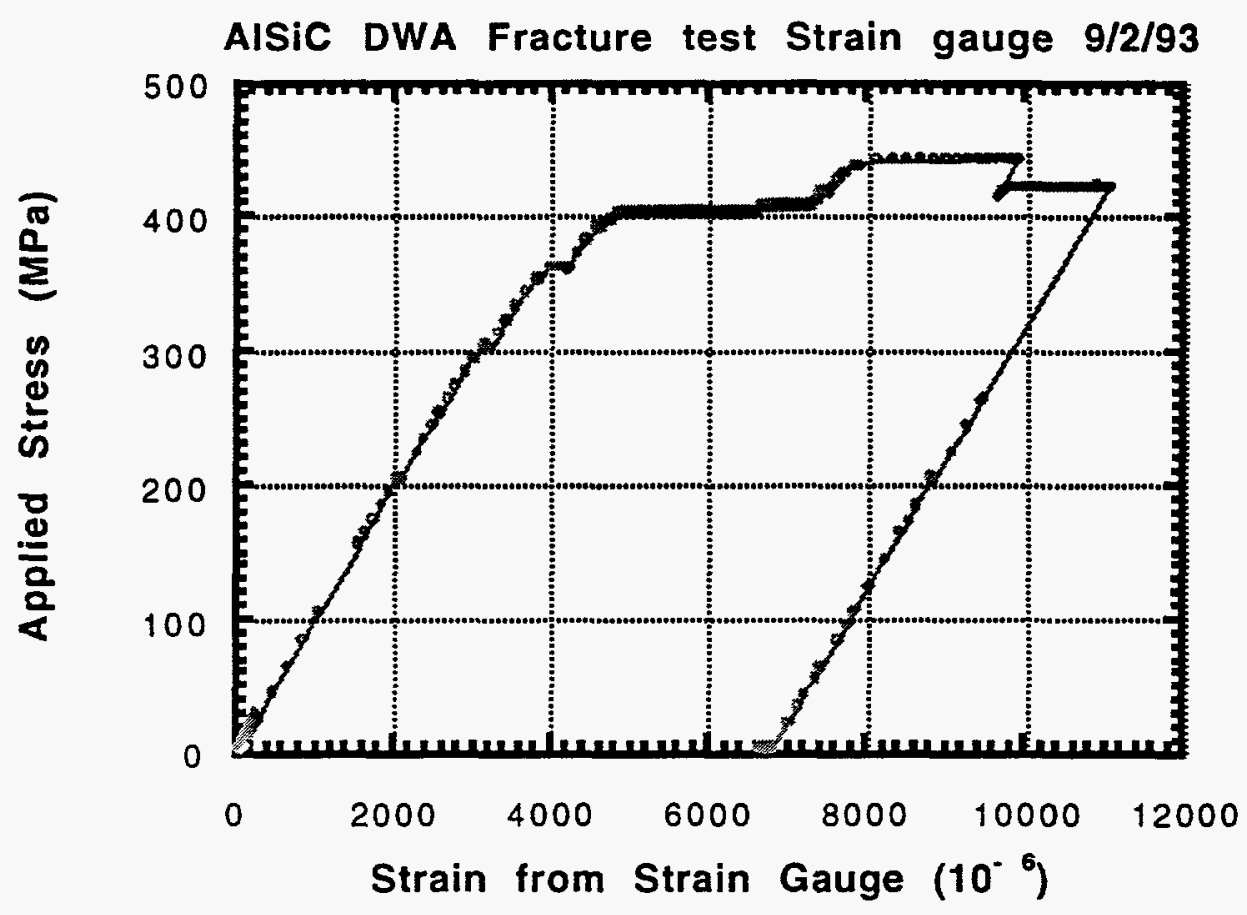

Figure 5: Stress-strain curve as measured by external strain gauge, where creep is represented by horizontal iso-stress strain elapse.

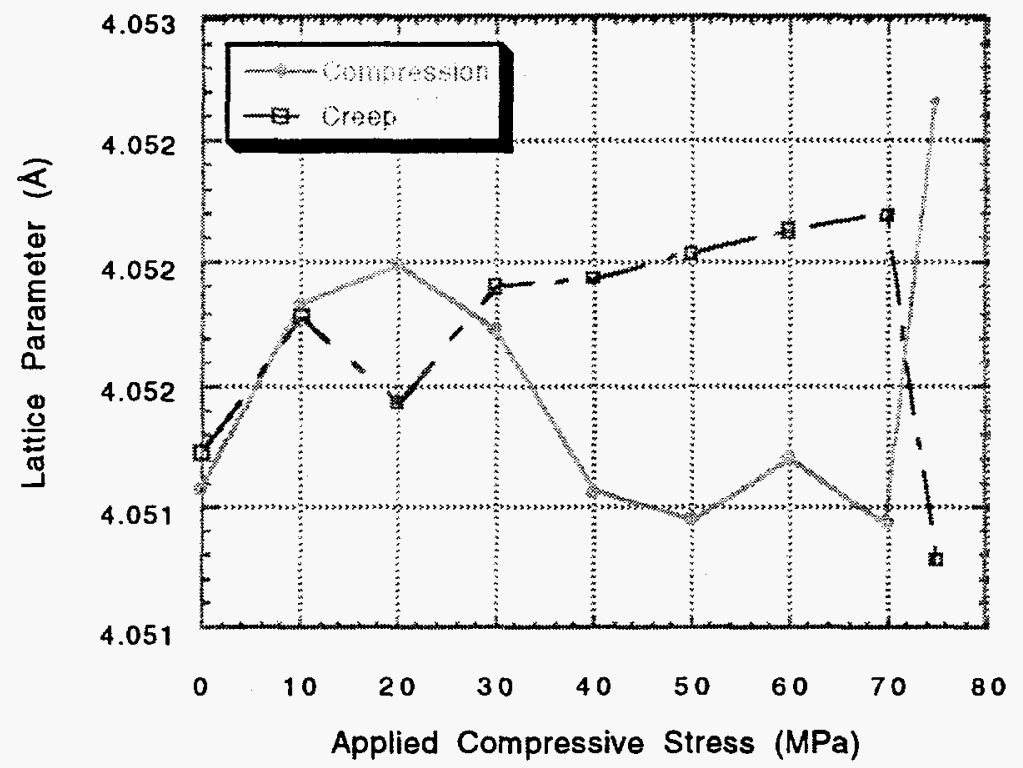

Figure 6: Lattice parameter of sample after compressive creep as compared with that under same static compression. 


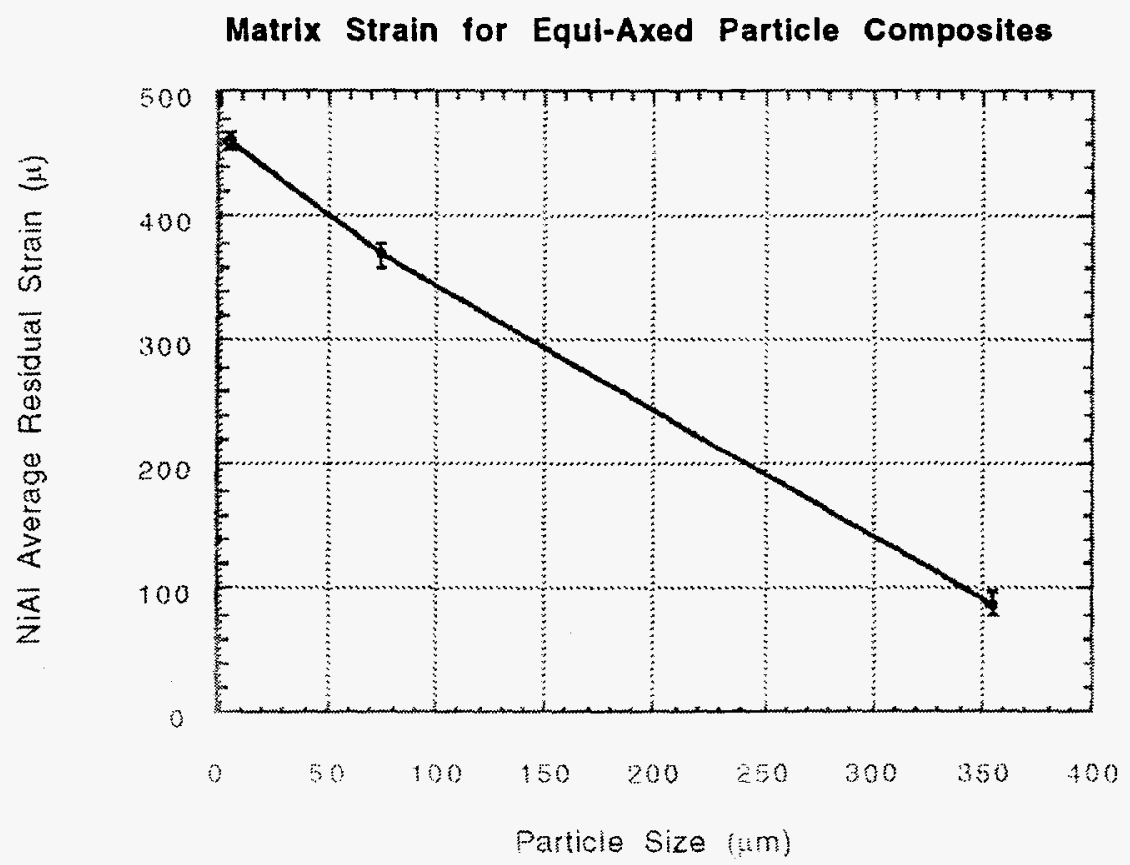

Figure 7: Measured NiAl thermal residual strains as a function of reinforcement size.

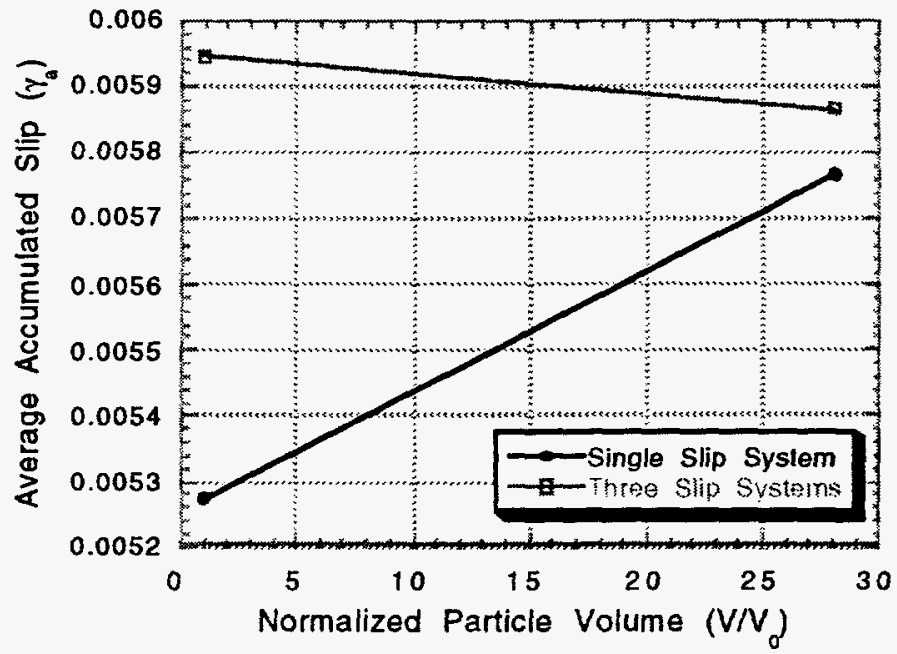

Figure 8: Calculated average accumulated slip vs. normalized individual particle volume for a multigrain aggregate. A comparison of single and three slip systems. 